\title{
Onco-miR-130 promotes cell proliferation and migration by targeting TGF $\beta$ R2 in gastric cancer
}

\author{
Jingjing Duan ${ }^{1, *}$, Haiyang Zhang ${ }^{1, *}$, Yanjun $Q u^{1, *}$, Ting Deng ${ }^{1}$, Dingzhi Huang ${ }^{1}$, Rui \\ Liu $^{1}$, Le Zhang ${ }^{1}$, Ming Bai ${ }^{1}$, Likun Zhou ${ }^{1}$, Guoguang Ying ${ }^{1}$, Yi Ba ${ }^{1}$ \\ ${ }^{1}$ Department of Gastrointestinal Oncology, Tianjin Medical University Cancer Institute and Hospital, National Clinical Research \\ Center for Cancer, Tianjin Key Laboratory of Cancer Prevention and Therapy, Tianjin, 300060, China \\ *These authors have contributed equally to this work \\ Correspondence to: Yi Ba, email: bayi@tjmuch.com \\ Guoguang Ying, email: yingguoguang163@163.com
}

Keywords: TGFBR2, miR-130, gastric cancer, proliferation, migration

Received: December 13,2015 Accepted: May 20,2016 Published: June 10, 2016

\section{ABSTRACT}

MicroRNAs (miRNAs) have been proved to play crucial roles in tumorigenesis. TGF $\beta$ signal pathway abnormality is found in various cancers and correlates with tumor proliferation and metastasis. However, the mechanisms underlying the dysregulation of TGF $\beta R 2$ expression in GC have not been investigated yet. In this study, we found that the TGF $\beta R 2$ protein was clearly repressed in tumor tissues, while miR-130 expression level was dramatically increased in GC tissues. Firefly luciferase activity assay revealed that miR-130 could directly bind to 3'UTR of TGF $\beta R 2$ mRNA. Meanwhile, miR-130 mimics lead to the decreased TGF $\beta R 2$ protein levels, while miR130 inhibitors enhanced TGF $\beta R 2$ expression in SGC7901 cells. Subsequent functional experiments showed that overexpressed miR-130 could promote proliferation and migration of SGC7901 cells. And siRNA-mediated TGF $\beta$ R2 down-regulation could simulate the effects of miR-130 mimics on phenotypes of SGC7901 cells. Furthermore, there existed intense relationship between the expression level of miR-130 and epithelial-mesenchymal markers. Our results demonstrated that miR-130 was an oncogene by directly targeting TGF $\beta R 2$ in GC.

\section{INTRODUCTION}

Gastric cancer (GC) is the fourth most common cancer worldwide [1]. The incidence rate of GC in Asian countries is higher than others, furthermore, China account for $42 \%$ in Asia [2]. With its aggressive properties and rather late stage at diagnosis, the prognosis of gastric cancer is still poor. Although great advance has been made in the diagnosis and treatment of GC, it could only improve curative effect of early disease, but not the curative effect in case of middle and late stages. Current treatment, such as chemotherapy and radiation, still cannot significantly prolong the survival time of gastric cancer patients. Targeted medicine, which is based on cancer gene therapy, can be a promising strategy in the treatment of gastric cancer [3]. However, the effective and comprehensive driven target used in treatment is limited in gastric cancer. Hence, many researchers focused on the mechanisms of GC oncogenesis to explore novel targets.
The transforming growth factor beta (TGF $\beta$ ) signaling pathway is known to be involved in many cellular processes, including cell growth, differentiation, apoptosis and cellular homeostasis [4]. TGF $\beta 1$ is a secretory cytokine that binds to the TGF $\beta$-receptor- 2 (TGF $\beta R 2$ ), which then complexes with the TGF $\beta$ receptor-1 (TGFßR1 or ALK1 or ALK5). This binding complexes activates TGF $\beta$ signaling via smad phosphorylation and nuclear translocation [5]. The TGF $\beta$ pathway is always aberrant in many diseases including cancers [6-8]. In diverse malignancies, TGF $\beta$ signaling has either tumor suppressive or pro-oncogenic functions in accordance with tumor stage $[9,10]$. The blockade of TGF $\beta$ signaling is always through either interrupt of TGF $\beta$ responses or the development of genetic alterations and epigenetic modifications in its components especially TGF $\beta R 2$ [11]. As a tumor-suppressor gene, TGF $\beta R 2$ is down-regulated in multiple cancer types [7, 12-14]. Then cancer cells lose their sensitivity to TGF $\beta$-mediated 
growth inhibitory effect due to TGF $\beta$ R2 down-regulation [15]. Although the role of TGF $\beta$ signaling pathway has been discovered, the mechanisms underlying the downregulation of TGF $\beta$ R2 expression especially in the tumorigenesis of GC have not been investigated yet.

MicroRNAs (miRNAs) are a class of small noncoding single-stranded RNA molecules of approximately 22 nucleotides, which are involved in a wide spectrum of biological processes including development [16], aging process [17], cell proliferation [8], cell apoptosis and the immune response [18]. MiRNAs lead to specific mRNA cleavage or translational repression through forming miRNA-induced silencing complexes and binding to the $3^{\prime}$-untranslated region (3'UTR) of target gene mRNA [19]. Abnormal expression of miRNAs act as essential modulators for carcinogenesis, chemotherapy resistance and tumor metastasis [19]. Recent years, serum miRNAs are regarded as novel biomarkers for the diagnosis and prognosis of various cancers [20, 21]. The properties that miRNAs are highly conserved in the genome and have a relatively high degree of tissue specificity make miRNAs ideal biomarkers for cancer identification. Our previous studies even show that miRNAs can be secreted into the extracellular environment through microvesicles (MVs) and function as secretory signaling molecules that influence the recipient cell phenotypes [22].

MiR-130 has been identified in modulating the porcine reproductive and respiratory syndrome virus (PRRSV) replication [23] and involved in matrix remodeling in pulmonary hypertension [24]. However, the role of miR-130 in tumorigenesis, especially in gastric cancer, has not been investigated yet. In our present study, we found that miR-130 is up-regulated, whileas TGF $\beta$ R2 expression is significantly suppressed in GC tissues. The subsequent luciferase assay showed that miR-130 can directly bind to the 3'UTR of the mRNA of TGF $\beta R 2$. The inhibition of TGF $\beta$ R2 in GC cells which was resulted from the overexpression of miR-130, promoted cell proliferation and migration. Therefore, our data illustrated that the novel miR-130-TGF $\beta$ R2 pathway play a key role in the tumorigenesis of $\mathrm{GC}$, which could act as a potential target in the future treatment of GC.

\section{RESULTS}

\section{TGF $\beta R 2$ is down-regulated in human gastric cancer tissues}

In order to discuss the role of TGF $\beta$ R2 in gastric carcinogenesis, expression of TGF $\beta$ R2 was detected by western blotting and qRT-PCR analyses. Six pairs of GC patient tissues and corresponding noncancerous tissues were collected in our study. Among those patients, there were 4 men and 2 women. The average age was 59 (range, 44-69). And all patients received radical gastrectomy without any complication. As shown in Figure 1A, the
TGF $\beta$ R2 protein was found to be significantly downregulated in GC tissues. However, the mRNA level of TGF $\beta$ R2 showed only slight decrease in GC tissues compared to the noncancerous tissues (Figure 1B). The expression characteristic of TGF $\beta$ R 2 was detected by using IHC assays in six pairs of formalin-fxed, paraffnembedded sections of tissue specimens. TGF $\beta 2$ is a well-known transmembrane protein, as shown in Figure $1 \mathrm{E}$, it is found to be mainly expressed in cell membrane, and however, due to strong positive of cell membrane in some epithelium cells, it also appeared weak positive in cytoplasm. The gland epithelium of gastric mucosa expressed most TGF $\beta R 2$. In accordance with the results of western blotting, TGF $\beta$ R2 is lowly expressed in the sections of cancer tissue specimens compared to corresponding noncancerous tissues. These results suggested that the expression of TGF $\beta$ R 2 mainly depends on the post-transcriptional regulation in GC.

\section{MiR-130 is up-regulated in GC tissues and directly targets TGF $\beta R 2$}

The miRNA-mediated specific mRNA cleavage or translational repression is one of the most important posttranscriptional regulatory mechanisms. In our study, we use three computational approaches to predict the potential target of miR-130. Based on the predictive results of bioinformatics tools, we find that miR-130 can directly target the 3'UTR of TGF $\beta R 2$ mRNA, and the free energy of all three computational algorithms show that miR-130 have high affinity with TGF $\beta$ R2. As shown in Figure $2 \mathrm{~A}$, the position that miR-130 directly targets is highly conserved, and miR-130 could binds with TGF $\beta$ R 2 mRNA by complementary base pairing of this target region. To validate the actual relationship of miR-130 and TGF $\beta$ R2 in GC, we firstly explored the level of miR-130 in six pairs of GC tissues and corresponding noncancerous tissues. As is expected, miR-130 showed obvious increase in all the tumor tissues (Figure 1D). The levels of miR-130 and TGF $\beta$ R2 showed inverse correlation in GC. Therefore, miR-130 is most likely to be the important regulator of TGF $\beta R 2$ in gastric cancer cells.

Then we conducted luciferase assay to investigate the direct interaction between miR-130 and TGF $\beta$ R2. In order to verify this targeting relationship, the miR130 binding sequence in the $3^{\prime}$-UTR of TGF $\beta R 2$ and the mutated $3^{\prime}$-UTR sequence were inserted into the downstream of the firefly luciferase reporter gene in p-MIR vector and then co-transfected with miR-130 mimics, inhibitors (or miRNA NC) into HEK293T cells and SGC7901 cells. As shown in Figure 2B, the relative luciferase activity of the reporter gene in SGC7901 cells co-transfected with p-MIR-TGF $\beta$ R2 and miR-130 mimics was significantly decreased by nearly $50 \%$ compared with the control (co-transfected with p-MIR-TGF $\beta$ R2 and miRNA NC), while the relative luciferase activity of 
the reporter gene in SGC7901 cells co-transfected with mutated p-MIR-TGF $\beta$ R2 and miR-130 mimics or miRNA $\mathrm{NC}$ was no different. The luciferase signal showed relative increase when miR-130 inhibitors were used instead. The results in HEK293T cells were shown in Supplementary Figure S1, the outcome was consistence with that in SGC7901 cells. Our results verified that miR-130 could suppress TGF $\beta$ R2 expression through miR-130 binding sequences at the 3'UTR of TGF $\beta$ R2 mRNA.

\section{MiR-130 regulates TGF $\beta R 2$ expression in SGC7901 cells}

In order to clarify the function of miR-130, miR-130 mimics or inhibitors were transfected into SGC7901 cell line. After $24 \mathrm{~h}$, the cells were collected for detecting miR130 levels by qRT-PCR analysis. Results showed that
miR-130 mimics could significantly increase miR-130 level in SGC7901 cells (Figure 2F), while miR-130 inhibitors decreased miR-130 level (Figure 2G). To further investigate if miR-130 affected TGF $\beta R 2$ expression at post-transcriptional level in GC cells, we performed qRT-PCR and Western blot to determine the mRNA and protein level of TGF $\beta$ R2 after the transfection of miR-130 mimics or inhibitors in SGC7901 cells. As shown in Figure $2 \mathrm{C}$ and $2 \mathrm{D}$, the overexpression of miR130 by transfection of mimics led to the clear suppression of TGF $\beta$ R2 protein, but not TGF $\beta$ R 2 mRNA. While the transfection of miR-130 inhibitors enhances the expression of TGF $\beta$ R2 in SGC7901 cells. Meanwhile, TGF $\beta R 2$ mRNA was not changed with the transfection of inhibitors. These data demonstrated that miR-130 is an important post-transcriptional regulator of TGF $\beta$ R2 in GC cells.
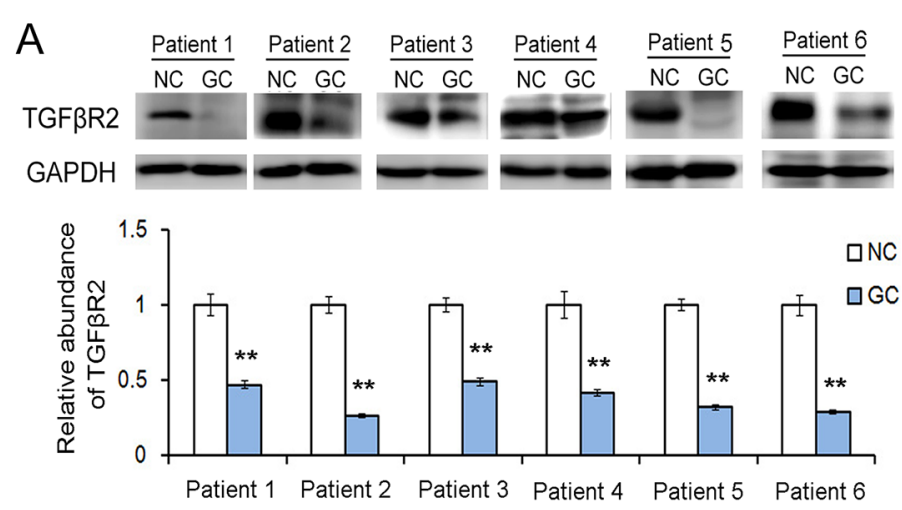

C

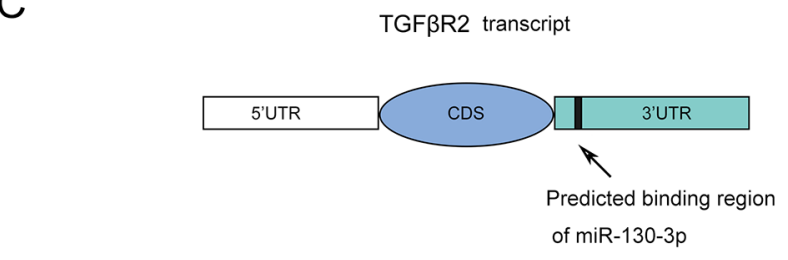

$E$
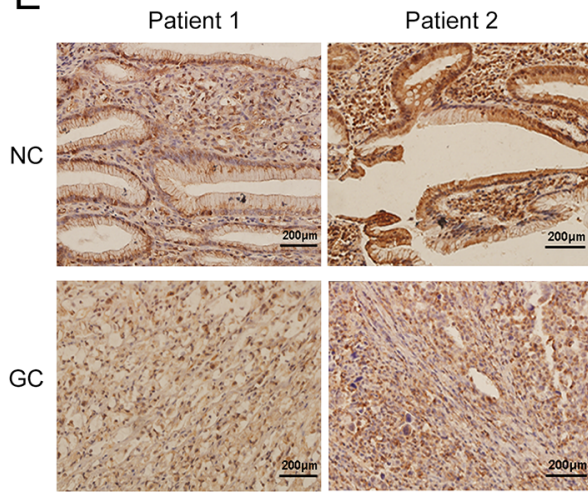

Patient 3
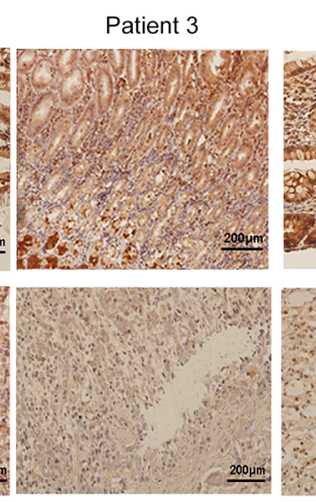
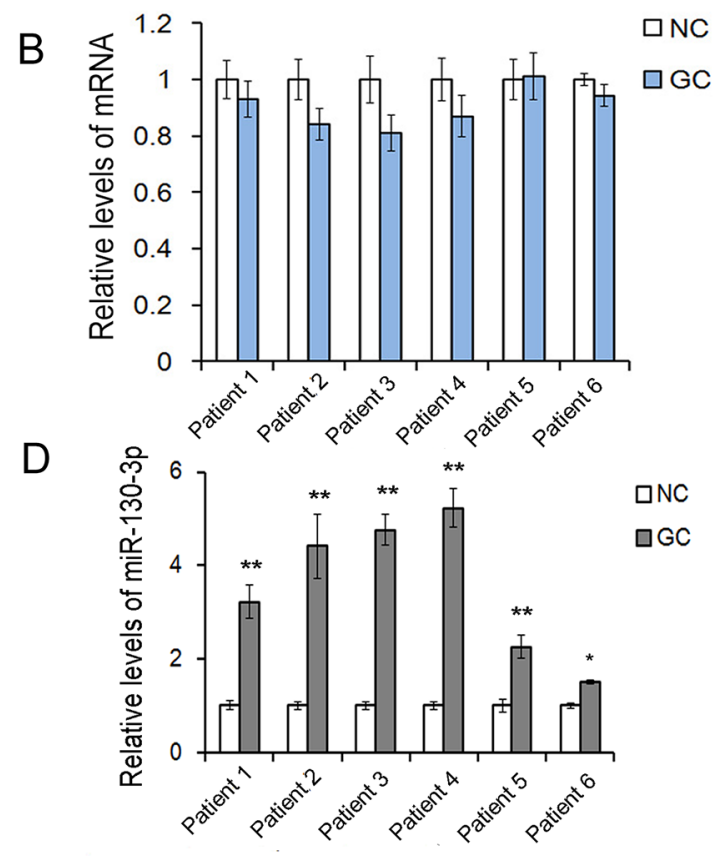

Patient 4

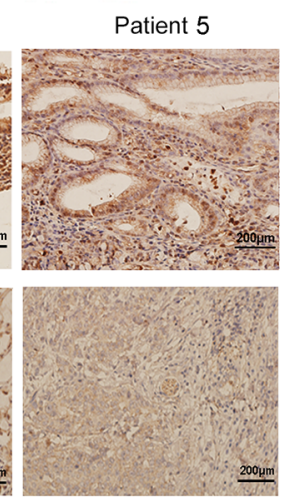

Patient 6

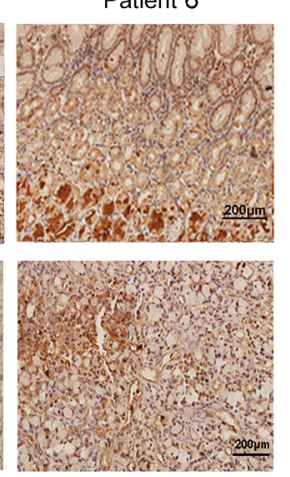

Figure 1: The expression patterns of TGF $\beta R 2$ and miR-130 in GC tissues. A. Western blot analysis of TGF $\beta$ R2 expression in GC cancer tissues and the paired adjacent noncancerous tissues $(n=6)$. B. Relative levels of TGF $\beta 22$ mRNA levels in GC tissues $(n=6)$. C. The predicted binding region of miR-130 in the mRNA of TGFßR2. D. Relative levels of miR-130 in GC tissues and para-carcinoma tissues $(\mathrm{n}=6)$. E. Immunohistochemistry assays of TGF $\beta R 2$ expression in GC cancer tissues $(\mathrm{n}=6)$. * indicates $P<0.05$; ** indicates $P<0.01$. 


\section{MiR-130 promotes cell proliferation and migration in SGC7901 cells}

The effect of miR-130 on the proliferation of SGC7901 cells was detected in vitro by the EdU proliferation assay (Figure 3C). The results revealed that the proliferation rate in SGC7901 cells transfected with miR-130 mimics was significantly increased compared with the control group. While, the proliferation rate in SGC7901 cells transfected with miR-130 inhibitors showed a sharp decrease than the NC inhibitor group. All these data showed that miR-130 could enhance the proliferation of SGC7901 cell line.

In order to determine whether miR-130 affected cell migration, wound healing method (Figure 3E) and transwell assay (Figure 3A) were performed after transfection with miR-130 mimics, inhibitors or miRNA NC in SGC7901 cell line. Both the wound healing method and transwell assay demonstrated that SGC7901 cells transfected with
miR-130 mimics showed a higher ratio in migration. On the contrary, cell migration was strongly inhibited when cells are transfected with miR-130 inhibitors. These results showed that miR-130 is an onco-miRNA in gastric cancer that could enhance proliferation and migration, and plays a key role in the tumorigenesis in cancer cells.

\section{Effects of TGF $\beta R 2$ overexpressing and silencing in SGC7901 cells}

To further understand TGF $\beta$ R2-regulated cell growth and migration in GC cells, we used plasmid to overexpress TGF $\beta$ R2 and siRNA targeting TGF $\beta$ R2 to down-regulate its expression. Firstly we explored the appropriate concentration of siRNA, and it was shown that the concentration of 100 pmol was appropriate (Supplementary Figure S2). As shown in Figure 4, the expression levels of TGF $\beta$ R 2 mRNA and protein
A

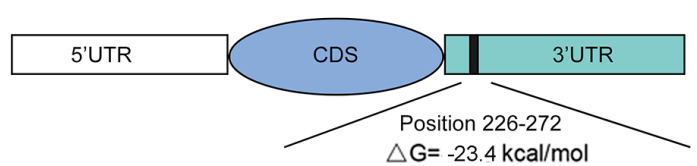

TGFBR2 $\mid$ rat 5 '...AAUAGCCAAUAACAUUUGCACUU GFR2 mouse 5' ...AAUAGCCAAUAACAUUUGCACUU human 5' ...AAUAGCCAAUAACAUUUGCACUU | || || || || ||| 'nsa-miR-130-3p 3' UACGGGAAAAUUGU-AACGUGAC

B

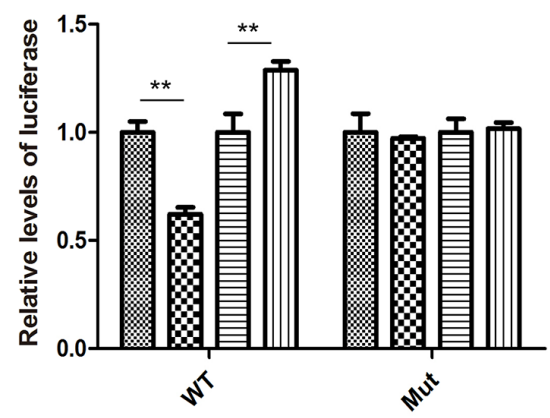

$\mathrm{F}$

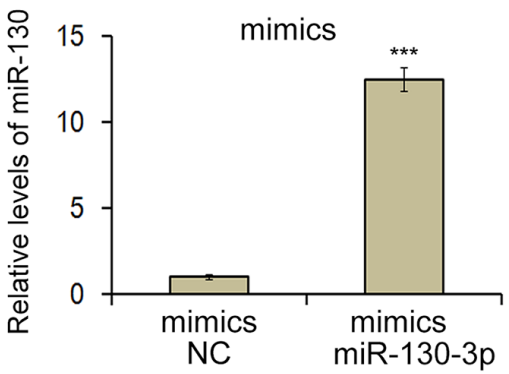

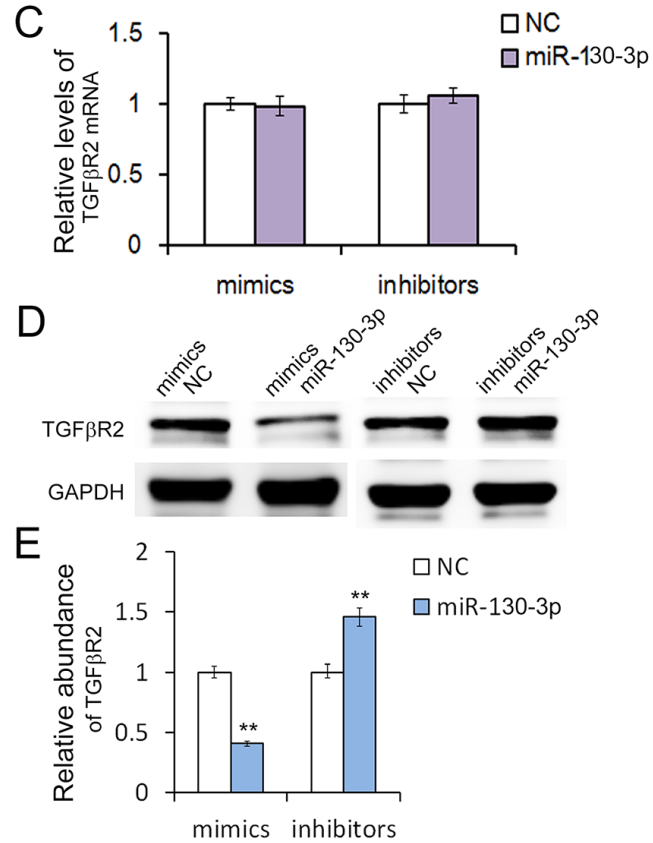

G

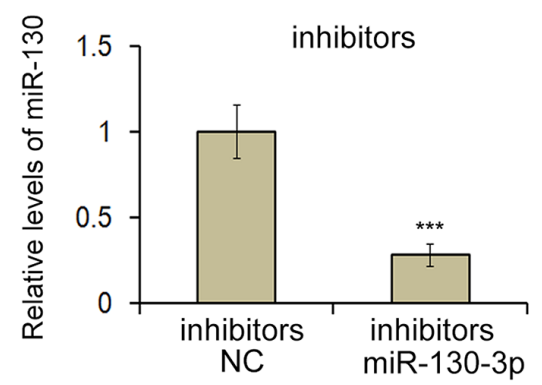

Figure 2: MiR-130 regulates TGFßR2 expression in gastric cancer cells. A. The predicted base-pairing interaction between miR-130 and TGFßR2 mRNA. B. Direct recognition of TGF $\beta$ R2 by miR-130. SGC7901 cells were co-transfected with firefly luciferase reporters containing either WT or mutant TGF $\beta R 2$ 3'UTR with miR-130 mimics and inhibitors ( $\mathrm{n}=3$ ). C. Quantitative RT-PCR analysis of TGF $\beta R 2$ mRNA levels in SGC7901 cells transfected with miR-130 mimics or inhibitors $(n=3)$. D. The suppression of TGF $3 R 2$ expression by miR-130 in SGC7901 cells (n=3). E. Quantitative analysis of D (n=3). F. and G. Quantitative RT-PCR analysis of miR-130 levels in SGC7901 cells transfected with mimics or inhibitors $(\mathrm{n}=3)$. ** indicates $P<0.01$; *** indicated $P<0.001$. 


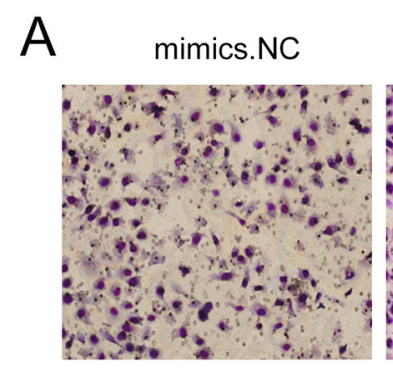

B

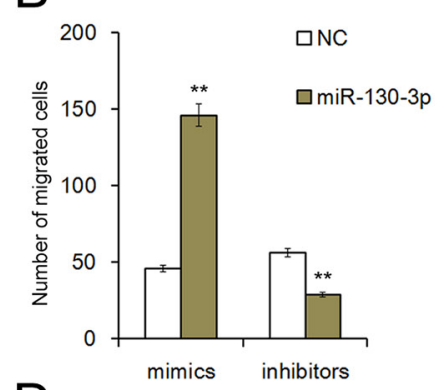

D
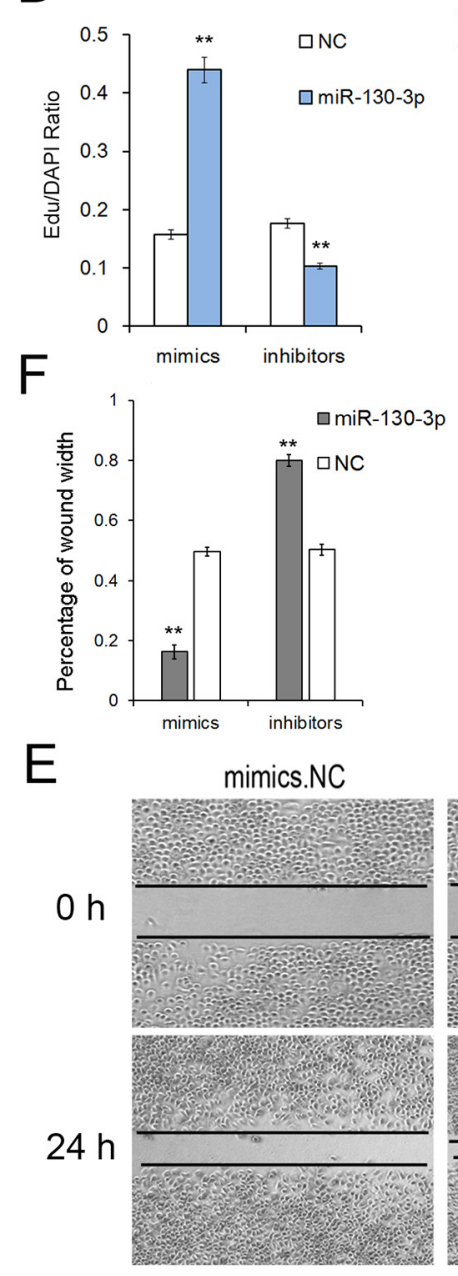

mimics miR-130-3p

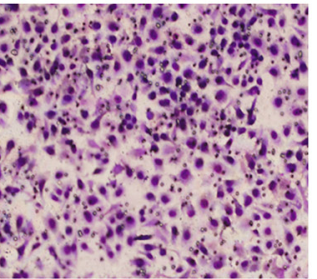

inhibitors.NC

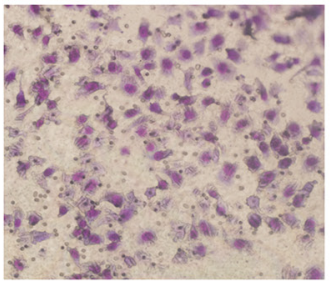

inhibitors miR-130-3p

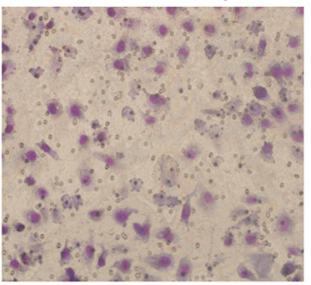

C
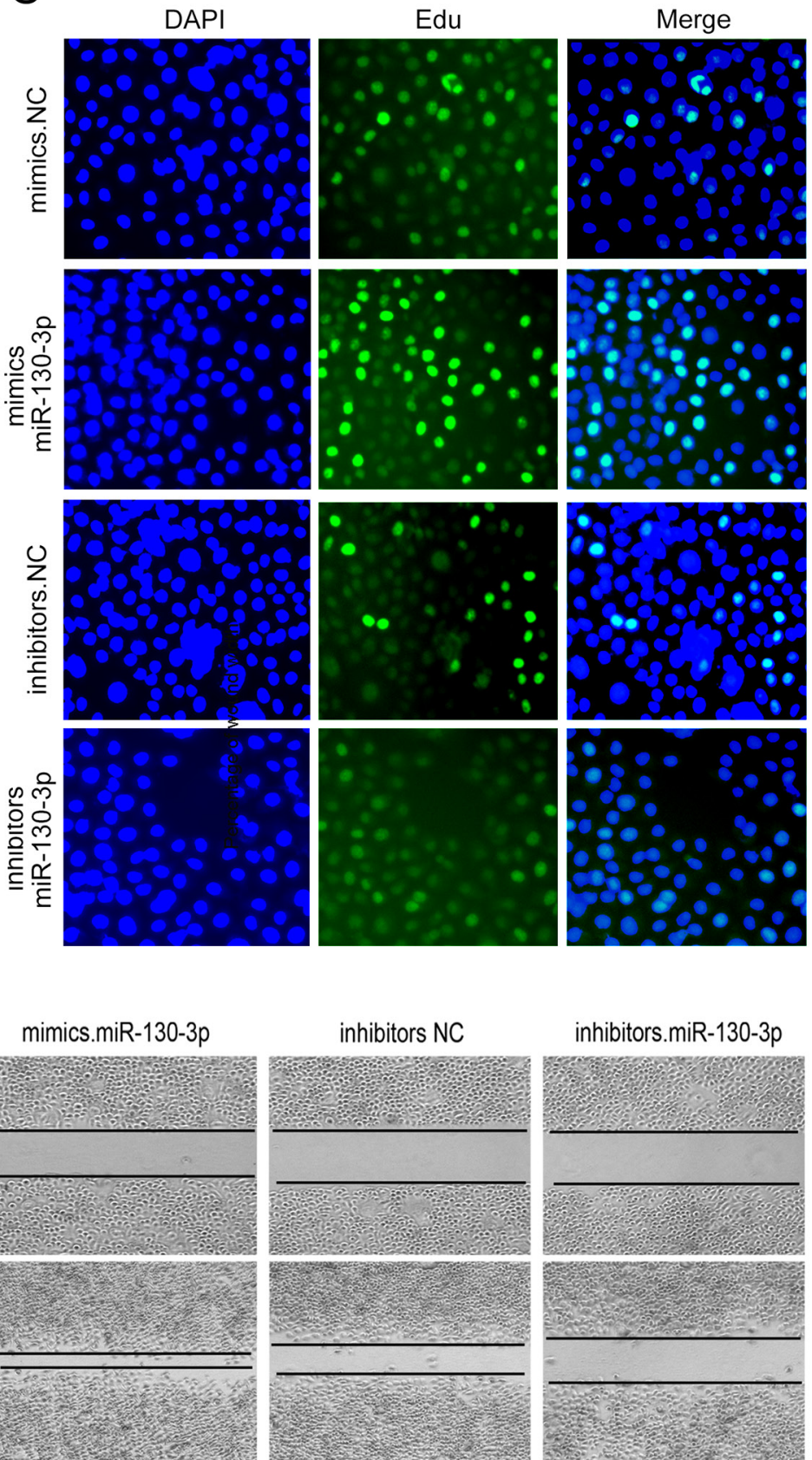

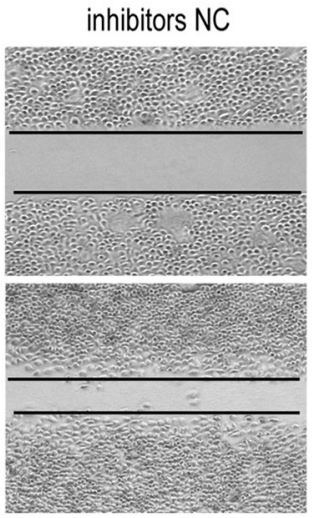

inhibitors.miR-130-3p

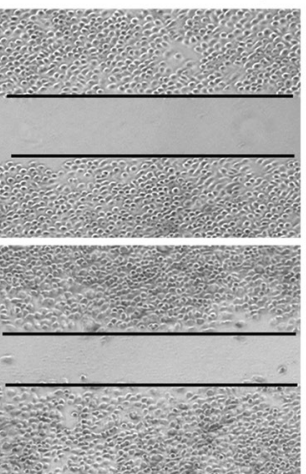

Figure 3: Onco-miR-130 promotes cell proliferation and migration of SGC7901 cells. A. Transwell assays show that miR130 promotes cell migration of GC cells $(n=3)$. B. Quantitative analysis of A $(n=3)$. C. MiR-130 enhances cell proliferation of SGC7901 cells $(n=3)$. D. Quantitative analysis of $C(n=3)$. E. Validation of miR-130-mediated cell migration by wound healing method $(n=3)$. $* *$ indicates $P<0.01$. 
were significantly up-regulated or down-regulated in SGC7901 cells transfected with TGF $\beta$ R2 plasmid or siRNA compared with control. Subsequently, the function of TGF $\beta$ R2 was also measured. The EdU proliferation assay (Figure 5C) indicated that the proliferation rate of SGC7901 cells transfected with TGF $\beta R 2$ plasmid was significantly lower than that of control cells, whereas siRNA targeting TGF $\beta$ R2 could promote proliferation. Furthermore, the downregulation of TGF $\beta$ R2 could promote cell migration significantly (Figure 5A and 5E). These results demonstrated that siRNA-mediated TGF $\beta$ R2 downregulation could mimic the effects of miR-130 upregulation in GC cells. Therefore, TGF $\beta$ R2 acts as a cancer suppresser in GC and its dramatic downregulation contributes to faster rate of proliferation and stronger ability of migration in cancer cells.

\section{The correlation of miR-130-TGF $\beta R 2$ pathway and epithelial-mesenchymal markers}

To further investigate the role of the miR-130TGF $\beta$ R2 pathway in gastric cancer cells, we checked for epithelial and mesenchymal markers by western blot analysis. As shown in Figure 6, it showed a mesenchymal phenotype after miR-130 overexpression or TGF $\beta$ R2 knock-down; whereas an epithelial phenotype when the expression level of miR-130 was inhibited or TGF $\beta$ R2 was up-regulated. The results emphasis the oncogenic role of miR-130 in GC cells.

\section{DISCUSSION}

Previous studies have clearly indicated that one miRNA could target multiple genes, while one gene could also be regulated by more than one miRNA. For example, miR-24 can target Bim [25] and FSCN1 [26], and Bim can both be mediated by miR-24 and miR-181b [27]. Therefore, identification and perfect the pathway connecting miRNA to their target genes will be helpful to highlight the functions of miRNA in various biological processes containing carcinogenesis.

In present study, we found that the TGF $\beta$ R 2 protein was clearly repressed in tumor tissues, while miR-130 expression level was dramatically increased in GC tissues. TGF $\beta$ R2 protein expression level was inversely correlated with miR-130 expression level in GC tissues, however, the mRNA level of TGF $\beta$ R2 showed only slight decrease in tumor tissues. Firefly luciferase activity assay revealed that miR-130 mimics could inhibit luciferase activity in the wild-type 3'UTR of TGF $\beta$ R2 mRNA but did not work in the mutant construct. Furthermore, miR-130 mimics lead to the decreased TGF $\beta$ R2 protein levels, while miR-130 inhibitors enhanced TGF $\beta$ R2 expression in SGC7901 cells. Subsequent functional experiments showed that overexpressed miR-130 could promote proliferation and migration of SGC7901 cells. And siRNA-mediated TGF $\beta$ R2 down-regulation could simulate the effects of miR-130 mimics on phenotypes of SGC7901 cells, while plasmid-mediated TGF $\beta$ R2 overexpression had the identical effects with miR-130 inhibitors. All these
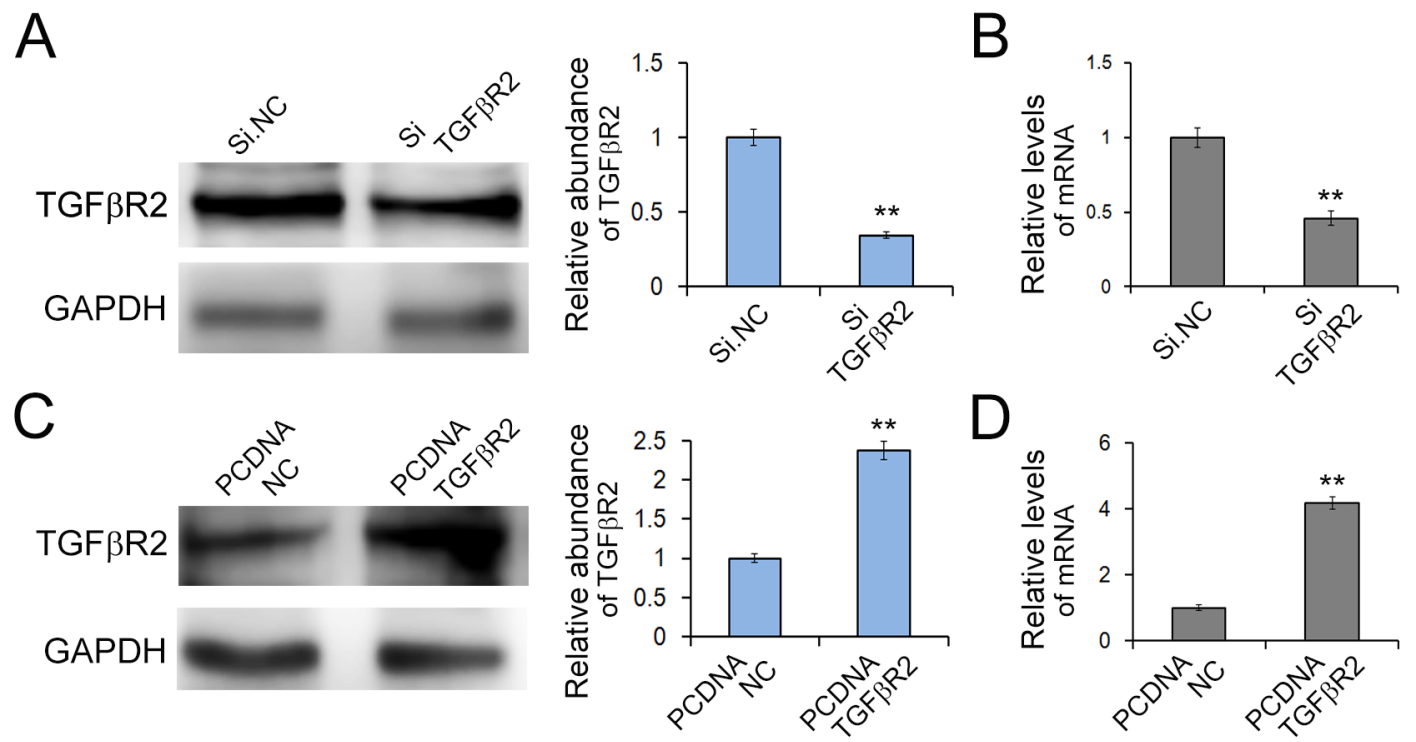

Figure 4: Effects of TGF $\beta$ R2 silencing and overexpressing in SGC7901 cells. A. and B. Knock-down of TGF $3 R 2$ expression by siRNA. SGC7901 cells were transfected with TGF $\beta$ R2 siRNA, and the protein levels (A) and mRNA levels (B) were detected respectively. $(n=3)$ C. and D. Up-regulation of TGF $\beta$ R2 expression by plasmid. SGC7901 cells were transfected with TGF $\beta$ R2 plasmid, and the protein levels (C) and mRNA levels (D) were detected respectively. PCDNA TGF $\beta$ R2 refers to overexpression plasmid, and PCDNA NC refers to control plasmid. (n=3) ** indicates $P<0.01$. 
A
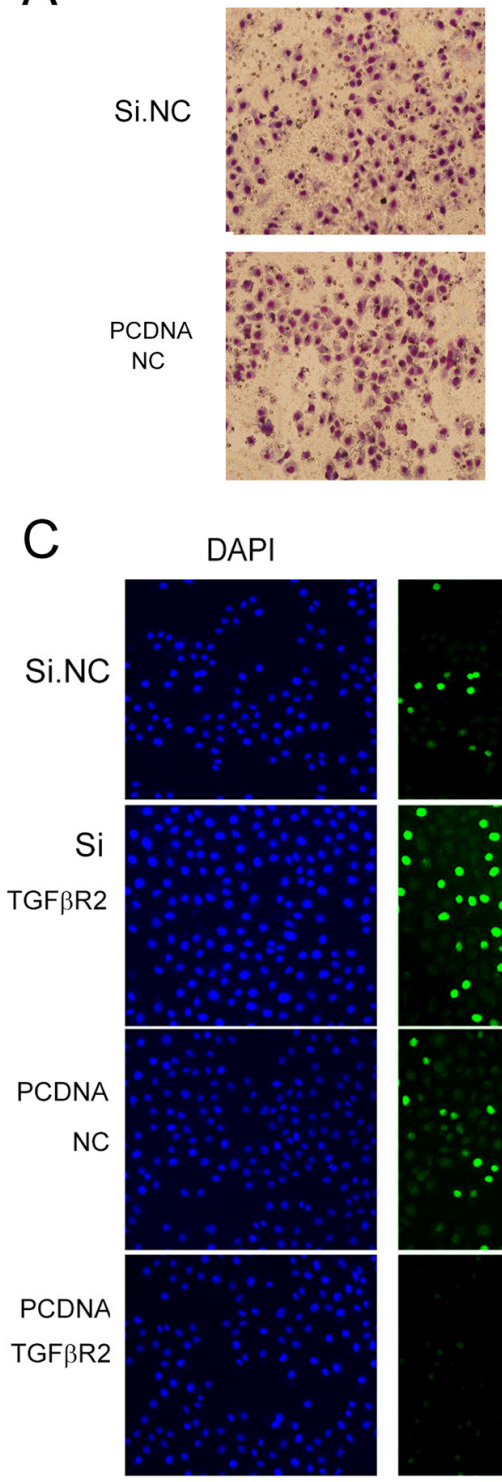

E

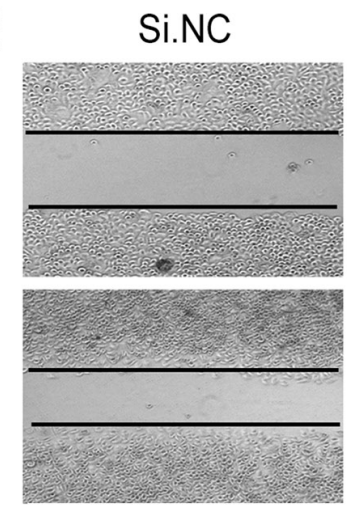

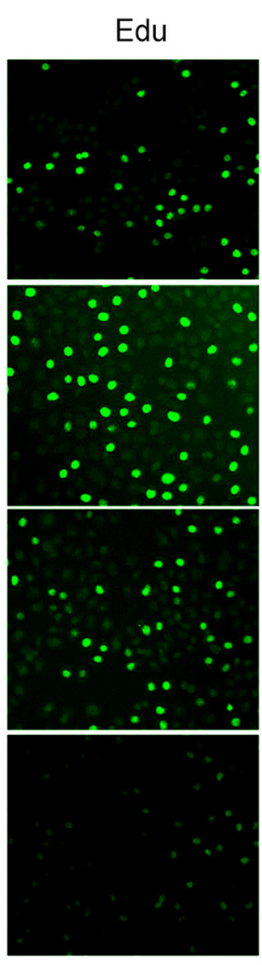

Si.TGF $\beta R 2$
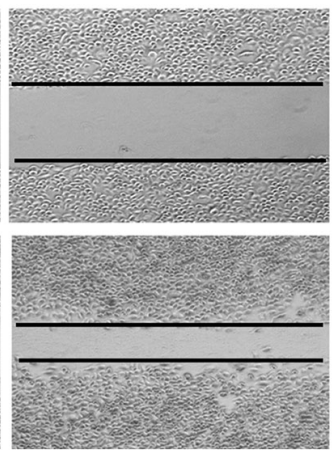

B
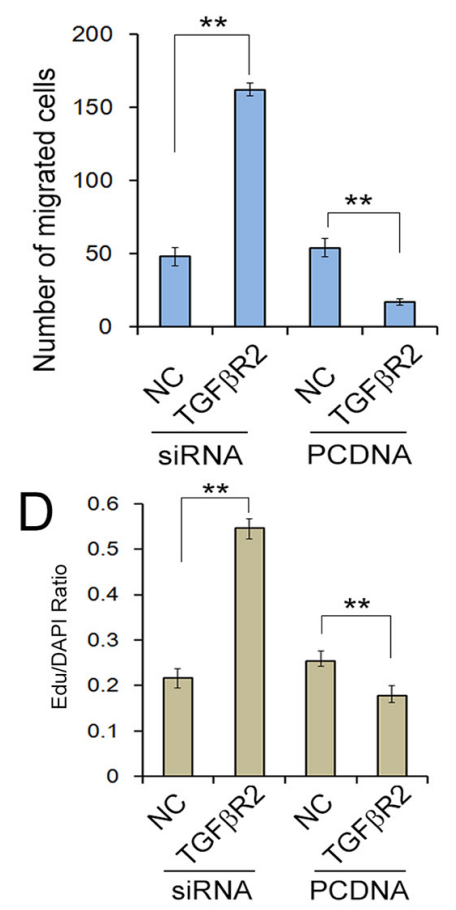

$\mathrm{F}$

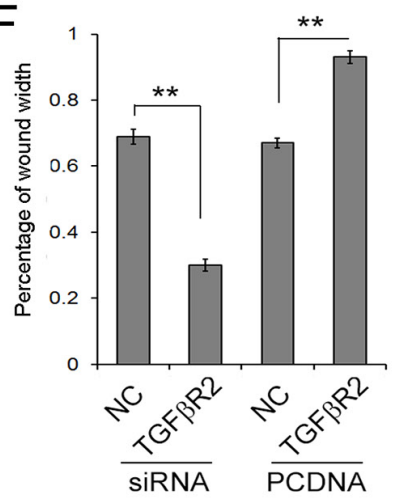

PCDNA

Figure 5: Identification of TGFßR2 as a tumor suppressor in GC. A. Transwell assays show that knock-down of TGFßR2 enhances cell migration of GC cells strongly $(n=3)$. B. Quantitative analysis of $A(n=3)$. C. Edu assays demonstrate that knock-down of TGF $\beta$ R2 promotes cell proliferation of SGC7901 cells $(\mathrm{n}=3)$. D. Quantitative analysis of C $(\mathrm{n}=3)$. E. Validation of TGF $\beta$ R2-mediated cell migration by wound healing method. PCDNA TGF $\beta 2$ refers to overexpression plasmid, and PCDNA NC refers to control plasmid. $(\mathrm{n}=3)$. ** indicates $P<0.01$. 

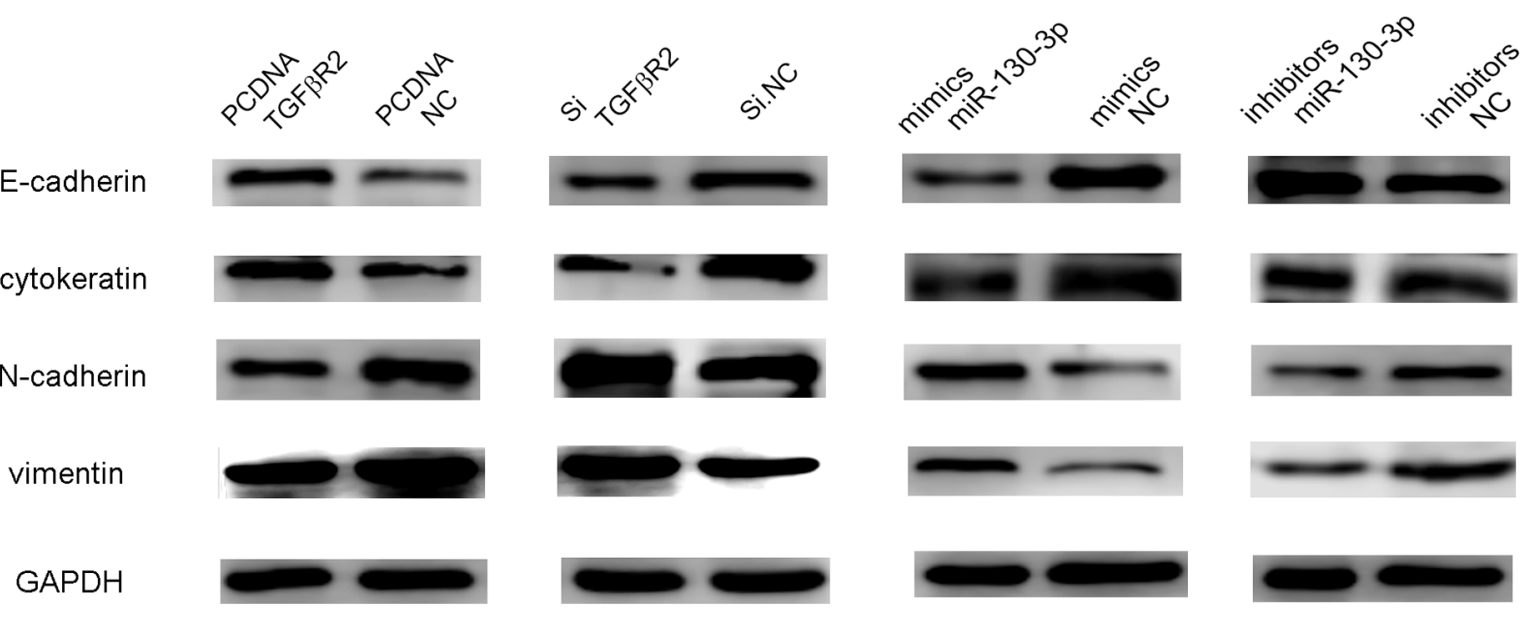

$\mathrm{B}$

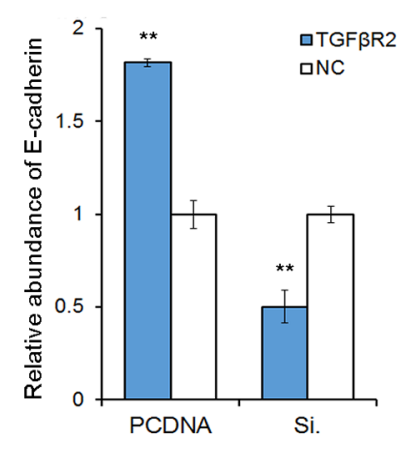

E-cadherin

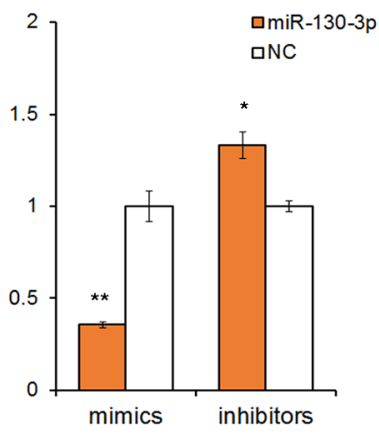

$\mathrm{N}$-cadherin

D
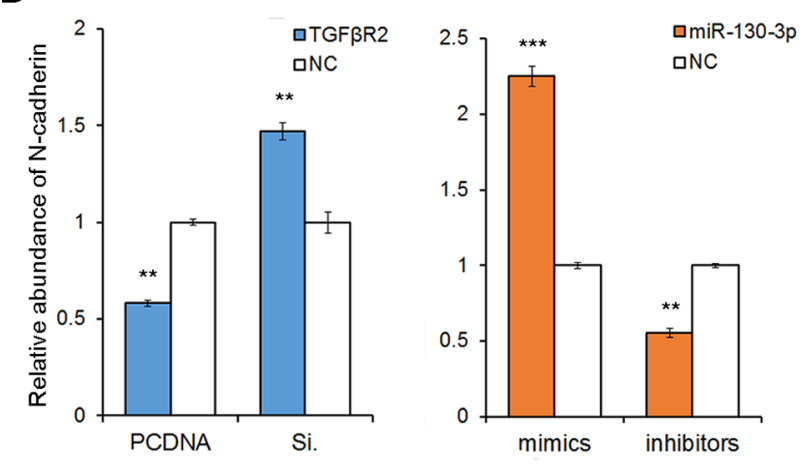

C

cytokeratin
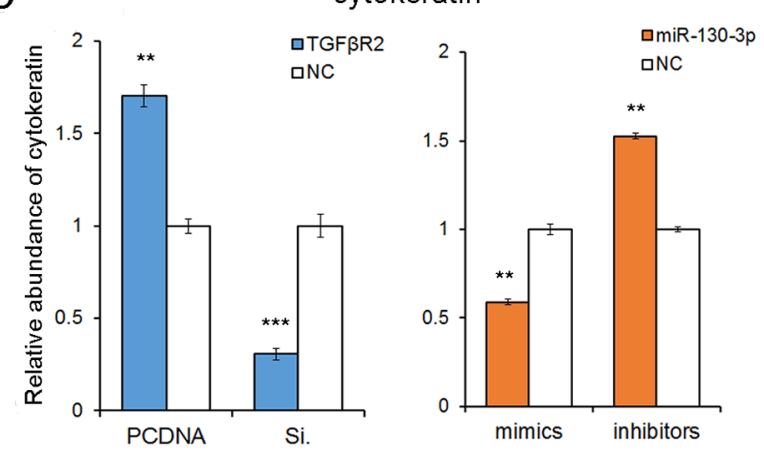

E

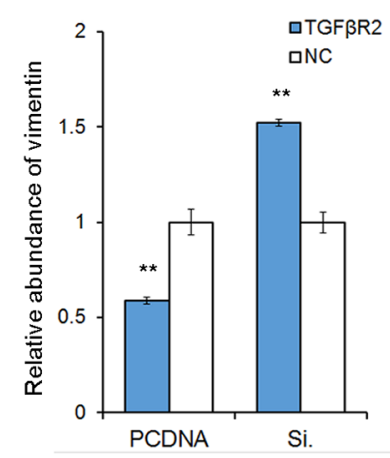

vimentin

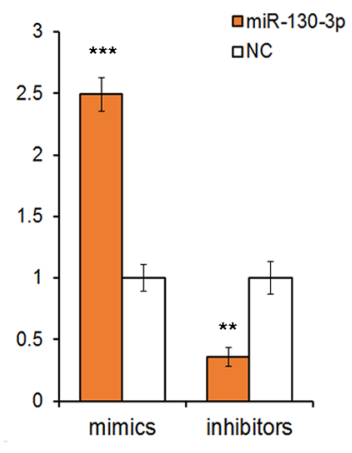

Figure 6: The correlation of miR-130-TGFßR2 axis and epithelial-mesenchymal markers. A. The results showed that the epithelial markers (E-cadherin and cytokeratin) were up-regulated when miR-130 was knockdown or TGF $\beta$ R2 was overexpressed. While, it showed a mesenchymal phenotype when miR-130 was up-regulated or TGFßR2 was inhibited. B, C, D and $\mathbf{E}$. Quantitative analyses of A. PCDNA TGF $\beta$ R2 refers to overexpression plasmid, and PCDNA NC refers to control plasmid. * indicates $P<0.05$; ** indicates $P<0.01$; *** indicated $P<0.001$.

data verified that miR-130 was an oncogene by directly targeting TGF $\beta R 2$ which functions as a tumor suppressor in GC. Finally, the relationship of miR-130 and epithelialmesenchymal markers emphasis the oncogenic role of miR-130. We believed that the secretion of onco-miR-130 from gastric cancer cells is reduced, resulting in the upregulation of miR-130 in cancer cells. However, this needs more evidence in further studies. Since we performed all experiments in only one gastric cancer cell line SGC7901, the effectiveness of miR-130 for GC in general needs more investigation.

TGF $\beta$ pathway is important in many life process including tumor development, but the role of TGF $\beta$ signaling pathway in tumorigenesis is controversial. Many papers demonstrated that TGF $\beta R 2$ functioned as a tumor suppressor and was down-regulated in some human cancers. Low levels 
of TGF $\beta$ R2 proteins were negatively correlated with poor survival in patients with nasopharyngeal carcinoma [13]. However, some researchers found that TGF $\beta$ R2 as a protooncogene, the expression was significantly higher in NSCLC tissues than in non-neoplastic tissues, and high expression of TGF $\beta$ R2 was a critical risk factor for reduced survival in NSCLC patients [7]. And in subsequently vitro experiments, TGF $\beta$ R2 could promote malignant characteristics in A549 [28] and H1299 cells [29]. However, the role of TGF $\beta$ R2 in GC tumorigenesis is unknown. Dys-regulation of miRNA expression in various cancers has been widely reported in both tumor tissues and serum [21, 30, 31]. Tissue miRNAs are highly conserved in the genome and could provide an accurate diagnosis for various types of malignancies, which usually lead to disorders of protein expression in cancer cells. To our knowledge, this is the first attempt to investigate the miR130-TGF $\beta$ R2 pathway in GC tissues and cells. Our results show that miR-130 act as an oncogenic miRNA in GC.

Currently, chemotherapy and radiotherapy are the two major viable strategies exist for the treatment of advanced GC. But resistance to chemotherapeutic drugs has become increasingly problematic in GC. It drives urgent need to detect new targets and treatment strategies. MiRNAs play a vital role in tumorigenesis, angiogenesis and drug resistance [32-34], and are proved to be a useful biomarker in the diagnosis and prognosis of cancer. Recently, miRNAs or anti-miRNAs trafficked by microvesicles (MV) or other plasmids have been used for the treatment of various diseases in mouse models, including cancers [22, 35, 36]. The translational research on miRNAs, including miR-130, will bring a new chapter in cancer gene therapy.

In conclusion, the miR-130-TGF $\beta$ R2 pathway is involved in the processes of cell growth and migration, thus regulating tumorigenesis in GC. Our study provided further evidence of the extensive role of miR-130 in the regulation of GC progression. Further studies are needed to explore its clinical application as potential molecular therapeutic target for human GC.

\section{MATERIALS AND METHODS}

\section{Human tissue}

Gastric cancer tissues and their paired adjacent noncancerous tissues were derived from patients undergoing a radical surgery at the Tianjin Medical University Cancer Institute and Hospital. Both tumor tissues were histopathologically verified adenocarcinoma and noncancerous tissues were confirmed negative. The study was approved by the the Ethics Committee of Tianjin Medical University Cancer Institute and Hospital and informed consent was obtained before surgery. Tissue fragments were immediately frozen in liquid nitrogen at the time of surgery. Total protein and RNA of those paired tissues were extracted and stored at $-80^{\circ} \mathrm{C}$.

\section{Cell culture}

Human gastric cell line SGC7901, human embryo kidney epithelial cell line HEK293T were cultured in RPIM1640 (Gibco, USA) or DMEM (Gibco, USA), which was supplemented with $10 \%$ fetal bovine serum (FBS, Gibco, USA) and 1\% penicillin-streptomycin in a humidified incubator at $37{ }^{\circ} \mathrm{C}$ with $5 \% \mathrm{CO}_{2}$ followed by suggestions.

\section{The miRNA target prediction and Luciferase reporter assay}

The miRNA target prediction and analysis were performed with the algorithms from TargetScan (http:// www.targetscan.org/), PicTar (http://pictar.mdc-berlin.de/) and miRanda (http://www.microrna.org/). The reporter plasmid p-MIR-TGF $\beta$ R2 containing the predicted miR-130 targeting regions was designed by Genescript (Nanjing, China). Part of the wild type and mutated 3'UTR of TGF $\beta$ R2 was cloned immediately downstream of the firefly luciferase reporter. The $\beta$-galactosidase expression vector (Ambion) was used as a transfection control. For the subsequent luciferase reporter assays, $2 \mathrm{mg}$ of firefly luciferase reporter plasmid, $2 \mathrm{mg}$ of $\beta$-galactosidase vector, and equal doses (200 pmol) of mimics, inhibitors, or scrambled negative control RNA were transfected into the prepared cells. At $24 \mathrm{~h}$ after transfection, cells were analyzed using the Dual Luciferase Assay Kit (Promega) according to the manufacturer's instructions. Each sample was prepared in triplicate, and the entire experiment was repeated three times.

\section{Cell transfection}

SGC7901 cells were plated in six-well or other plates and performed transfection after 24 hours. The TGF $\beta$ R2 overexpressing plasmid (PCDNA TGF $\beta$ R2) and the control plasmid (PCDNA NC)were bought from GenePharma (Shanghai, China), and $2 \mu \mathrm{g}$ of plasmid were transfected into every single well. Cells were transfected with scrambled negative control, miR-130 mimics or inhibitors using lipofectamine 2000 (Invitrogen, Life Technologies) and Opti-MEM Reduced Serum Medium (Gibco, Life Technologies) according to the manufacturer's instructions. And equal amounts (100 pmol) of miRNA mimics, inhibitors, siRNAs (Santa Cruz), or scrambled negative control RNA were transfected into each well. Then the cells were harvested at $24 \mathrm{~h}$ after transfection for real-time quantitative PCR analysis and at $48 \mathrm{~h}$ for western blotting.

\section{RT-PCR}

Total RNA was extracted from the cultured cells and tissues using TRIzol Reagent (Invitrogen) following the manufacturer's protocol. The quantity of miRNA was 
performed using Taqman microRNA probes (Applied Biosystems, Foster City, CA). After the reactions were accomplished, the cycle threshold (CT) data were determined using fixed threshold settings, and the mean $\mathrm{CT}$ was calculated from triplicate PCRs. A comparative $\mathrm{CT}$ method was used to compare each condition to the control reactions. U6 snRNA was used as an internal control of miRNAs, and the mRNA levels of TGF $\beta$ R2 was normalized to the corresponding housekeeping gene GAPDH. The relative amount of gene normalized to control was calculated with the equation $2^{-\triangle C T}$, in which $\Delta \mathrm{CT}=\mathrm{CT}$ gene $-\mathrm{CT} \mathrm{control}$. All of the reactions were run in triplicate. Primers of TGF $\beta R 2$ and GAPDH were as follows:

5'-AGAAGGCTGGGGCTCATTTG-3' (GAPDH,
sense);
5'-AGGGGCCATCCACAGTCTTC-3' (GAPDH,
antisense);
5'-GTAGCTCTGATGAGTGCAATGAC-3' (TGFßR2,
sense);
5'-CAGATATGGCAACTCCCAGTG-3' (TGFßR2,
antisense).

\section{Western blotting}

The TGF $\beta$ R 2 expression was assessed by western blotting analysis and samples were normalized to GAPDH. Total protein were extracted from the cultured cells and tissues were solubilized in lysis buffer. The protein were separated by sodium dodecyl sulfate-polyacrylamide gel electrophoresis and then transferred to polyvinylidene difluoride membranes (Roche). The membranes were blocked within $2 \%$ Bovine Serum Albumin (BSA) at room temperature for $1 \mathrm{~h}$ and incubated overnight at 4 ${ }^{\circ} \mathrm{C}$ with primary anti-TGF $\beta$ R2 (1:200, Santa Cruz), and anti-GAPDH (1:5000, Santa Cruz), respectively. The membranes subsequently washed and incubated with appropriate secondary antibodies. After incubated with ECL, the protein bands were visualized.

\section{Cell proliferation assay}

The proliferative ability of SGC7901 cells after different transfection were determined by the EdU proliferation assay (RiboBio Inc.). Twenty-four hours after transfection, cells were incubated in $50 \mathrm{M} \mathrm{EdU} \mathrm{for}$ $5 \mathrm{~h}$, and fixed within $4 \%$ paraformaldehyde for $30 \mathrm{~min}$ at room temperature (RT). Then the cells were washed in PBS twice and permeabilized using PBS containing $0.5 \%$ Triton X-100 for $10 \mathrm{~min}$. After extensive washes in PBS, the cells were incubated lucifugally in Apollo staining solution (RiboBio Inc.) for $30 \mathrm{~min}$, then repeated permeation and wash, and incubated in Hoechst 33342 (1:100; RiboBio Inc.) for another 30 min at RT. All of the staining were performed in triplicate.

\section{Cell migration assay}

Wound healing assay and transwell-chamber (Corning, New York, USA) migration assay were used to determine the migrative capacity of transfected cells. When the cells attached, a wound healing assay was performed. After washing with PBS, medium with $1 \%$ FBS was added. Then, at the indicated time points of 0 hour, 6 hours, 18 hours and 24 hours, cells were observed and photographs were taken. The distance of the wound zone in each well was measured at least three randomly selected fields and compared with control. After $24 \mathrm{~h}$ of post-transfection, cells were transferred into the upper chamber of the transwell with $200 \mu 1$ serum-free growth medium $\left(10^{5}\right.$ cells per well of $8.0 \mu \mathrm{m}$ Pore Polycarbonate Membrane Insert). Complete medium containing $10 \%$ FBS was added to the lower chamber as a chemo-attractant. After $24 \mathrm{~h}$ of incubation at $37^{\circ} \mathrm{C}$, nonmigratory cells on the upper surface of upper chamber were removed slightly by cotton swabs, and cells that migrated to the bottom of the membrane were fixed and stained. The number of invaded cells was counted under light microscope. To minimize the bias, five randomly selected fields with $200 \times$ magnification were counted, then the average number was calculated.

\section{Immunohistochemistry assays}

Formalin-fxed, paraffn-embedded sections of tissue specimens including gastric adenocarcinoma and paired adjacent noncancerous tissues were reviewed by pathologists. TGF $\beta R 2$-examinations in tissues were performed on 8- $\mu \mathrm{m}$-thick paraffin sections. All sections were deparaffnized twice with xylene and rehydrated in a graded series of ethanol. The sections were soaked in 10 $\mathrm{mmol} / \mathrm{L}$ citrate buffer $(\mathrm{pH}$ 6.0) for antigen retrieval, and heated to $220^{\circ} \mathrm{C}$ in high pressure for 3 minutes. Endogenous peroxidase activity was blocked by soaking in $3 \%$ hydrogen peroxide for 20 minutes. The sections were then incubated overnight at $4^{\circ} \mathrm{C}$ with anti-human TGF $\beta R 2$ monoclonal antibody (1:50, Santa Cruz, sc-400). The next day, the slides were washed in PBS and incubated with second antibodies for 40 minutes at $37^{\circ} \mathrm{C}$. After washes with PBS, 3-amino-9ethylcarbazole solution were used to chromogen. Then the sections were counterstained with hematoxylin, dehydrated, and coverslipped. Quantitative analysis was conducted by quantifying the fluorescence intensity from six sections.

\section{Statistical analyses}

All statistical analyses were performed using IBM SPSS Statistics, Version 20.0. All data were representative of at least three independent experiments. Data were described with median values \pm SME and analyzed by using the Student's t test for 2-group comparisons. Differences were considered statistically significant for $P<0.05$. In this study, ' $*$ ' indicates ' $P<0.05^{\prime}$, ' $* *$ ' indicates ' $P<0.01$ ', and '***' indicates ' $P<0.001$ '. 


\section{CONFLICTS OF INTEREST}

The authors declare that there is no conflict of interests regarding the publication of this article.

\section{GRANT SUPPORT}

This work was supported by the National Natural Science Foundation of China (Nos.81372394), Tianjin health and family planning commission foundation of science and technology (15KG142). This work was supported by grants from National research platform of clinical evaluation technology for new anticancer drugs (No. 2013ZX09303001) and Ministry of Education Research Fund for doctoral program (No. 20121202120013). The funders had no role in study design; collection, analysis, and interpretation of data; in the writing of the report; and in the decision to submit this article for publication.

\section{Author contributions}

Jingjing Duan, Haiyang Zhang and Yanjun Qu performed most of the experiments, analyzed data, and wrote the manuscript. Ting Deng, Rui Liu and Le Zhang reviewed and edited the manuscript. Ming Bai and Likun Zhou performed some experiments. Yi Ba, Dingzhi Huang and Guoguang Ying designed the experiments and edited the manuscript. Yi $\mathrm{Ba}$ is the guarantor of this work, and have full access to all of the data in the study and takes responsibility for the integrity of the data and the accuracy of the data analysis.

\section{REFERENCES}

1. Ferro A, Peleteiro B, Malvezzi M, Bosetti C, Bertuccio P, Levi F, Negri E, La Vecchia C and Lunet N. Worldwide trends in gastric cancer mortality (1980-2011), with predictions to 2015, and incidence by subtype. European journal of cancer (Oxford, England : 1990). 2014; 50:1330-1344.

2. Power DG, Kelsen DP and Shah MA. Advanced gastric cancer--slow but steady progress. Cancer treatment reviews. 2010; 36:384-392.

3. Hohenberger P and Gretschel S. Gastric cancer. Lancet. 2003; 362:305-315.

4. Moustakas A and Heldin $\mathrm{CH}$. The regulation of TGFbeta signal transduction. Development (Cambridge, England). 2009; 136:3699-3714.

5. Alejandre-Alcazar MA, Kwapiszewska G, Reiss I, Amarie OV, Marsh LM, Sevilla-Perez J, Wygrecka M, Eul B, Kobrich S, Hesse M, Schermuly RT, Seeger W, Eickelberg $\mathrm{O}$ and Morty RE. Hyperoxia modulates TGF-beta/ BMP signaling in a mouse model of bronchopulmonary dysplasia. American journal of physiology Lung cellular and molecular physiology. 2007; 292:L537-549.

6. Sureshbabu A, Syed MA, Boddupalli CS, Dhodapkar MV, Homer RJ, Minoo P and Bhandari V. Conditional overexpression of TGFbetal promotes pulmonary inflammation, apoptosis and mortality via TGFbetaR 2 in the developing mouse lung. Respiratory research. 2015; 16:4.

7. Han Y, Jia C, Cong X, Yu F, Cai H, Fang S, Cai L, Yang H, Sun Y, Li D, Liu J, Xie R, Yuan X, Zhong X, Li M, Wei $\mathrm{Q}$, et al. Increased Expression of TGFbetaR2 Is Associated with the Clinical Outcome of Non-Small Cell Lung Cancer Patients Treated with Chemotherapy. PloS one. 2015; 10:e0134682.

8. Haj-Salem I, Fakhfakh R, Berube JC, Jacques E, Plante S, Simard MJ, Bosse Y and Chakir J. MicroRNA-19a enhances proliferation of bronchial epithelial cells by targeting TGFbetaR2 gene in severe asthma. Allergy. 2015; 70:212-219.

9. Meulmeester E and Ten Dijke P. The dynamic roles of TGF-beta in cancer. The Journal of pathology. 2011; 223:205-218.

10. Yang L, Pang Y and Moses HL. TGF-beta and immune cells: an important regulatory axis in the tumor microenvironment and progression. Trends in immunology. 2010; 31:220-227.

11. Levy L and Hill CS. Alterations in components of the TGFbeta superfamily signaling pathways in human cancer. Cytokine \& growth factor reviews. 2006; 17:41-58.

12. Ostapoff KT, Cenik BK, Wang M, Ye R, Xu X, Nugent D, Hagopian MM, Topalovski M, Rivera LB, Carroll KD and Brekken RA. Neutralizing murine TGFbetaR2 promotes a differentiated tumor cell phenotype and inhibits pancreatic cancer metastasis. Cancer research. 2014; 74:4996-5007.

13. Zhang W, Zeng Z, Fan S, Wang J, Yang J, Zhou Y, Li X, Huang D, Liang F, Wu M, Tang K, Cao L, Li X, Xiong $\mathrm{W}$ and Li G. Evaluation of the prognostic value of TGFbeta superfamily type I receptor and TGF-beta type II receptor expression in nasopharyngeal carcinoma using high-throughput tissue microarrays. Journal of molecular histology. 2012; 43:297-306.

14. Yu Y, Kanwar SS, Patel BB, Oh PS, Nautiyal J, Sarkar FH and Majumdar AP. MicroRNA-21 induces stemness by downregulating transforming growth factor beta receptor 2 (TGFbetaR2) in colon cancer cells. Carcinogenesis. 2012; 33:68-76.

15. Mishra S, Deng JJ, Gowda PS, Rao MK, Lin CL, Chen CL, Huang T and Sun LZ. Androgen receptor and microRNA-21 axis downregulates transforming growth factor beta receptor II (TGFBR2) expression in prostate cancer. Oncogene. 2014; 33:4097-4106.

16. Reinhart BJ, Slack FJ, Basson M, Pasquinelli AE, Bettinger JC, Rougvie AE, Horvitz HR and Ruvkun G. The 21-nucleotide let-7 RNA regulates developmental timing in Caenorhabditis elegans. Nature. 2000; 403:901-906.

17. Machida T, Tomofuji T, Ekuni D, Maruyama T, Yoneda T, Kawabata Y, Mizuno H, Miyai H, Kunitomo M and 
Morita M. MicroRNAs in Salivary Exosome as Potential Biomarkers of Aging. International journal of molecular sciences. 2015; 16:21294-21309.

18. Schickel R, Boyerinas B, Park SM and Peter ME. MicroRNAs: key players in the immune system, differentiation, tumorigenesis and cell death. Oncogene. 2008; 27:5959-5974.

19. Bartel DP. MicroRNAs: genomics, biogenesis, mechanism, and function. Cell. 2004; 116:281-297.

20. Liu R, Chen X, Du Y, Yao W, Shen L, Wang C, Hu Z, Zhuang R, Ning G, Zhang C, Yuan Y, Li Z, Zen K, Ba Y and Zhang CY. Serum microRNA expression profile as a biomarker in the diagnosis and prognosis of pancreatic cancer. Clinical chemistry. 2012; 58:610-618.

21. Liu R, Zhang C, Hu Z, Li G, Wang C, Yang C, Huang D, Chen X, Zhang H, Zhuang R, Deng T, Liu H, Yin J, Wang S, Zen $\mathrm{K}, \mathrm{Ba} \mathrm{Y}$, et al. A five-microRNA signature identified from genome-wide serum microRNA expression profiling serves as a fingerprint for gastric cancer diagnosis. European journal of cancer (Oxford, England : 1990). 2011; 47:784-791.

22. Liu Y, Zhao L, Li D, Yin Y, Zhang CY, Li J and Zhang Y. Microvesicle-delivery miR-150 promotes tumorigenesis by up-regulating VEGF, and the neutralization of miR150 attenuate tumor development. Protein \& cell. 2013; 4:932-941.

23. Li L, Gao F, Jiang Y, Yu L, Zhou Y, Zheng H, Tong W, Yang S, Xia T, Qu Z and Tong G. Cellular miR-130b inhibits replication of porcine reproductive and respiratory syndrome virus in vitro and in vivo. Scientific reports. 2015; 5:17010.

24. Bertero T, Cottrill KA, Lu Y, Haeger CM, Dieffenbach P, Annis S, Hale A, Bhat B, Kaimal V, Zhang YY, Graham BB, Kumar R, Saggar R, Saggar R, Wallace WD, Ross DJ, et al. Matrix Remodeling Promotes Pulmonary Hypertension through Feedback Mechanoactivation of the YAP/TAZmiR-130/301 Circuit. Cell reports. 2015; 13:1016-1032.

25. Liu R, Zhang H, Wang X, Zhou L, Li H, Deng T, Qu Y, Duan J, Bai M, Ge S, Ning T, Zhang L, Huang D and Ba Y. The miR-24-Bim pathway promotes tumor growth and angiogenesis in pancreatic carcinoma. Oncotarget. 2015; 6:43831-43842. doi: 10.18632/oncotarget.6257.

26. Li YQ, Lu JH, Bao XM, Wang XF, Wu JH and Hong WQ. MiR-24 functions as a tumor suppressor in nasopharyngeal carcinoma through targeting FSCN1. J Exp Clin Cancer Res. 2015; 34:130.

27. Zheng Y, Lv X, Wang X, Wang B, Shao X, Huang Y, Shi L, Chen Z, Huang J and Huang P. miR-181b promotes chemoresistance in breast cancer by regulating Bim expression. Oncology reports. 2015.

28. Xu CC, Wu LM, Sun W, Zhang N, Chen WS and Fu XN. Effects of TGF-beta signaling blockade on human A549 lung adenocarcinoma cell lines. Molecular medicine reports. 2011; 4:1007-1015.

29. Ma ZL, Hou PP, Li YL, Wang DT, Yuan TW, Wei JL, Zhao BT, Lou JT, Zhao XT, Jin Y and Jin YX. MicroRNA-34a inhibits the proliferation and promotes the apoptosis of non-small cell lung cancer H1299 cell line by targeting TGFbetaR2. Tumour Biol. 2015; 36:2481-2490.

30. Wang C, Hu J, Lu M, Gu H, Zhou X, Chen X, Zen K, Zhang CY, Zhang T, Ge J, Wang J and Zhang C. A panel of five serum miRNAs as a potential diagnostic tool for earlystage renal cell carcinoma. Scientific reports. 2015; 5:7610.

31. Luo Y, Wang C, Chen X, Zhong T, Cai X, Chen S, Shi Y, Hu J, Guan X, Xia Z, Wang J, Zen K, Zhang CY and Zhang C. Increased serum and urinary microRNAs in children with idiopathic nephrotic syndrome. Clinical chemistry. 2013; 59:658-666.

32. Long J, Ji Z, Jiang K, Wang Z and Meng G. miR-193b Modulates Resistance to Doxorubicin in Human Breast Cancer Cells by Downregulating MCL-1. BioMed research international. 2015; 2015:373574.

33. Li F, Xu Y, Deng S, Li Z, Zou D, Yi S, Sui W, Hao M and Qiu L. MicroRNA-15a/16-1 cluster located at chromosome 13 q14 is down-regulated but displays different expression pattern and prognostic significance in multiple myeloma. Oncotarget. 2015; 6:38270-38282. doi: 10.18632/ oncotarget.5681.

34. De Mattos-Arruda L, Bottai G, Nuciforo PG, Di Tommaso L, Giovannetti E, Peg V, Losurdo A, Perez-Garcia J, Masci G, Corsi F, Cortes J, Seoane J, Calin GA and Santarpia L. MicroRNA-21 links epithelial-to-mesenchymal transition and inflammatory signals to confer resistance to neoadjuvant trastuzumab and chemotherapy in HER2positive breast cancer patients. Oncotarget. 2015; 6:3726937280. doi: 10.18632/oncotarget.5495.

35. Pan S, Yang X, Jia Y, Li Y, Chen R, Wang M, Cai D and Zhao R. Intravenous injection of microvesicle-delivery miR-130b alleviates high-fat diet-induced obesity in C57BL/6 mice through translational repression of PPARgamma. Journal of biomedical science. 2015; 22:86.

36. Li J, Zhang Y, Liu Y, Dai X, Li W, Cai X, Yin Y, Wang Q, Xue Y, Wang C, Li D, Hou D, Jiang X, Zhang J, Zen $\mathrm{K}$, Chen $\mathrm{X}$, et al. Microvesicle-mediated transfer of microRNA-150 from monocytes to endothelial cells promotes angiogenesis. The Journal of biological chemistry. 2013; 288:23586-23596. 